\title{
THE EFFECTS OF VARIOUS AMINO ACIDS ON PERIPHERAL BLOOD FLOW AND SKIN TEMPERATURE ${ }^{1}$
}

\author{
BY MARTIN B. MACHT 2 \\ WITH THE techNical assistance of ELIZABETH L. PILLION \\ (From the Quartermaster Corps, Climatic Research Laboratory, Lawrence, Mass.)
}

(Received for publication January 8, 1948)

Increases in skin temperature and peripheral blood flow following the ingestion of food have been reported by previous investigators (1 to 4 ). In 1941, Abramson and Fierst (5), using the venous occlusion plethysmograph, studied the effects of various dietary components upon peripheral blood flow in man. Following the ingestion of a predominantly carbohydrate meal, they found no significant change in total blood flow through the peripheral vascular beds of the hand, forearm or leg. Following the ingestion of a protein meal, however, an augmentation in blood flow became manifest in the hand, reaching its highest level 2 to $2 \frac{1}{2}$ hours after ingestion. A similar, though less marked, increase in flow was noted in the forearm and leg.

In view of the increase in oxygen consumption which occurs as a result of the specific dynamic action (S.D.A.) of protein, it might be postulated that the rises in skin temperature and blood flow subsequent to a protein meal bear a causal relationship to this phenomenon. Elevated skin temperatures in hyperthyroid patients have been observed by numerous investigators ( 6 to 8 ), and increases in blood flow have also been reported $(9,10)$. However, no consistent correlation between peripheral blood flow and basal metabolic rate was established by either Eichna and Wilkins (9) or Abramson and Fierst (10).

The S.D.A. of a protein is equal to the summated effects of its constituent amino acids (11). Recently, Gubner, DiPalma and Moore $(12,13)$ have reported increases in peripheral blood flow and skin temperature following the ingestion of glycine (amino-acetic acid). Although no quantitative parallelism between changes in oxygen consumption and peripheral blood flow were demon-

\footnotetext{
1 Read at the symposium on military physiology, regional meeting of the American Physiological Society, Washington, D. C., December 6, 1947 (34).

2 Formerly Captain, M.C.
}

strated in their subjects, these authors concluded that the increase in blood flow resulted from the S.D.A. of glycine.

In an effort to determine the effects of various amino acids upon peripheral blood flow and skin temperature, and to examine the possible relationships between S.D.A. and the peripheral circulation, in the present study seven amino acids were administered to four healthy male subjects. S.D.A. is not influenced by the work of the digestive glands, intestinal movements or work of absorption from the intestines, since the effect of amino acids is the same whether they be administered orally, intravenously or subcutaneously (14, 15). For this reason, all of the amino acids used in these experiments were given orally. Oxygen consumption, skin temperatures, rectal temperature and blood flow through the hand were determined before and after ingestion of these compounds. The results obtained are presented in this paper.

\section{METHODS}

Measurements of skin and rectal temperatures, blood flow through the hand, and oxygen consumption were collected on four healthy, white male subjects whose ages ranged from 17 to 21 years. All studies were conducted in a constant temperature room with closed circuit ventilation and a turbulent air velocity of approximately three m.p.h. The experiments were carried out at three different ambient temperatures: $18^{\circ} \mathrm{C}$., $24^{\circ} \mathrm{C}$., and $30^{\circ} \mathrm{C}$. The room temperature was controlled to within $\pm 0.5 \mathrm{C}$. during any experimental day.

Skin temperatures were obtained with No. 30 B \& S copper-constantan thermocouples connected to a Leeds and Northrup potentiometer. The thermal junctions were secured to the skin with small pieces of light adhesive tape and were placed as follows: forehead, right great toe, right forearm, abdomen, left thigh, and back. On the left hand ten thermocouples were connected in parallel (with six on the hand and four on the fingers) so that one temperature reading represented an average value for this hand. Rectal temperatures were recorded by means of a thermocouple at the tip of a No. 14 soft rubber catheter inserted at least $5 \mathrm{~cm}$. above the internal rectal sphincter. 
Oxygen consumption was determined by gas analysis of samples of expired air which were collected in a 100 liter Tissot apparatus.

A hand plethysmocalorimeter (16) was used as an air plethysmograph and blood flow.records were obtained by the venous occlusion method with a modified Brodie bellows. Each blood flow determination consisted of the average of seven consecutive flows taken at one-minute intervals. Flows were calculated in terms of cubic centimeters per 100 cubic centimeters of limb volume per minute.

On the night preceding an experiment, the subject was required to be in bed by 10 p.m. He was permitted no food or liquid other than water from this time until the end of the experimental period, the only material ingested being the particular compound studied that day.

The subject, wearing a light cotton undershirt, light cotton shorts, fatigue trousers, light woolen socks, and standard service shoes, entered the test chamber at 7:30 a.m. and remained at rest for approximately two hours. At the conclusion of this period, the skin and rectal thermocouples were put in place, the subject reclined comfortably in an adjustable chair and the left hand was inserted in the plethysmograph at heart level. Effort was made to allay apprehension and to minimize disturbing extraneous stimuli. Skin temperatures were measured until a steady state had been attained, i.e., until the average hand skin temperature remained unchanged within $\pm 0.2 \mathrm{C} .^{\circ}$ for no less than 40 minutes. When the steady state had been reached, blood flow records were obtained and the oxygen consumption was measured.

Following these procedures, the amino acid being studied was administered orally. Each drug was dissolved (or suspended when insoluble) in $300 \mathrm{cc}$. of unsweetened grapefruit juice at room temperature. The dosages were calculated in terms of grams of compound per pound of body weight. In the case of glycine, amounts ranging from 1 to 4 grams $/ 10 \mathrm{lbs}$. of body weight were employed. ${ }^{3}$ Most of the other amino acids investigated were used in dosages of 1-2 grams per $10 \mathrm{lbs}$. body weight. The amino acids used were: glycine, $\mathrm{dl}$ phenylalanine, $1(-)$ tyrosine, $1(-)$ leucine, $1(+)$ glutamic acid, $1(+)$ histidine and $\mathrm{dl}$ methionine. ${ }^{4}$

Average hand skin temperatures were measured every ten minutes and all skin and rectal temperatures were recorded at 30-minute intervals. Blood flow through the left hand was usually determined at 30-minute intervals or whenever a significant change in hand skin temperature was observed.

Oxygen consumption was, in most cases, obtained approximately 80 minutes and 200 minutes following ingestion of the amino acid. Subjective reactions were obtained by questioning and were recorded throughout each experiment. Similarly, any visible flushing, perspiration, etc. were noted in the protocols.

\footnotetext{
3 For certain technical reasons, the dosages used have been expressed in terms of $1,2,3$, and 4 grams per 10 lbs. body weight. These are equal to $.22, .44, .66$ and .88 grams per kilogram body weight, respectively.

4 The amino acids were kindly supplied by Merck \& Co.
}

All experiments were continued for at least three hours following administration of the amino acid unless the subject complained of an uncomfortable subjective reaction.

Control studies, using $300 \mathrm{cc}$. of plain, unsweetened grapefruit juice, but otherwise identical in every respect to those described above, were conducted at each ambient temperature.

\section{EXPERIMENTAL RESULTS}

\section{Glycine (aminoacetic acid)}

Glycine was administered in dosages of 1 gram per $10 \mathrm{lbs}$. body weight (seven experiments on two men), 2 grams per 10 lbs. body weight (18 experiments on four men), 3 grams per 10 lbs. body weight (five experiments on two men), and 4 grams per $10 \mathrm{lbs}$. body weight (three experiments on one man) for a total of 33 experiments.

\section{Subjective reactions}

The principal adverse symptoms encountered following the oral administration of glycine were nausea and/or vague abdominal discomfort usually described as "a feeling of fullness." These reactions generally occurred immediately or within 15 minutes after swallowing the amino acid and, in most cases, disappeared within one hour. There were few complaints referable to the sweetish taste of the substance. Threshold for nausea varied from man to man but was quite constant for any one subject. Thus, Subject A experienced no discomfort from dosages up to and including 3 grams $/ 10$ lbs. body weight, but complained of severe nausea after the administration of 4 grams/ 10 lbs. body weight. Subject B was not adversely affected by 2 grams/10 lbs. body weight but was barely able to tolerate 3 grams/10 lbs. body weight. Subjects C and D invariably reported slight to severe nausea after receiving 2 grams/10 lbs. body weight. Four experiments, discontinued because of vomiting within two hours after administration of the drug, were discarded and are not included in the protocols.

On only one occasion was any subjective impression of increased warmth reported. This was accompanied by severe nausea and dizziness and occurred after a massive dose of glycine (4 grams/ $10 \mathrm{lbs}$. body weight). This was also the only instance in which any marked flushing of the face or extremities was noted. 
Anorexia, lasting from three to eight hours after ingestion of the glycine, was a constant finding in all subjects. During the entire investigation, however, there was no significant weight change in any subject.

Studies at an environmental temperature of $24^{\circ} \mathrm{C}$.

Skin temperature. At an environmental temperature of $24^{\circ} \mathrm{C}$., ingestion of glycine in each of the four dosages employed caused a definite rise in skin temperature of the hand as compared with the controls. Once equilibrium had been reached, the hand skin temperature remained remarkably constant in the control series, the average maximum increase being only $0.4 \mathrm{C}{ }^{\circ}$ The average maximum increases in hand skin temperatures following the administration of $1,2,3$, and 4 grams of glycine $/ 10 \mathrm{lbs}$. body weight were $3.5 \mathrm{C} .^{\circ}$, $4.8 \mathrm{C} .^{\circ}, 5.4 \mathrm{C} .^{\circ}$, and $7.7 \mathrm{C} .^{\circ}$, respectively. These results are highly significant from a statistical standpoint (variance analysis, Student's " $t$ " test, Bartlett's test using chi-square), the probability being less than .01 that the differences between the control series and the glycine series were due to chance (17). ${ }^{5}$

5 The statistical analyses were made by Miss Agnes M. Galligan, whose aid is gratefully acknowledged.
Since 2 grams of glycine/10 lbs. body weight appeared to be the optimum dosage for producing peripheral vascular changes unaccompanied by nausea, the largest number of studies was conducted with this amount of the drug. A statistical comparison of the increments of hand skin temperature increases after glycine, 2 grams $/ 10 \mathrm{lbs}$. body weight, vs. the increments of hand skin temperature increase of controls was carried out in an effort to determine the relationship between time of ingestion and increase in hand temperature. Skin temperature readings were compared at 20 minute intervals (Figure 1). No significant difference between the control and the glycine series could be demonstrated 60 minutes after ingestion. At 80 minutes, the controls showed an average decrease of $0.22 \mathrm{C} .^{\circ}$ and the glycine series showed an average increase of $0.49 \mathrm{C}^{\circ}$. This difference is significant, the probability being less than .05 that it could be due to chance. At 120 minutes the difference between controls and glycine was greater and the probability is less than .01 that the difference was due to chance. One hundred and eighty minutes after administration of the drug the difference between the control and the glycine series was most marked and statistically most significant.

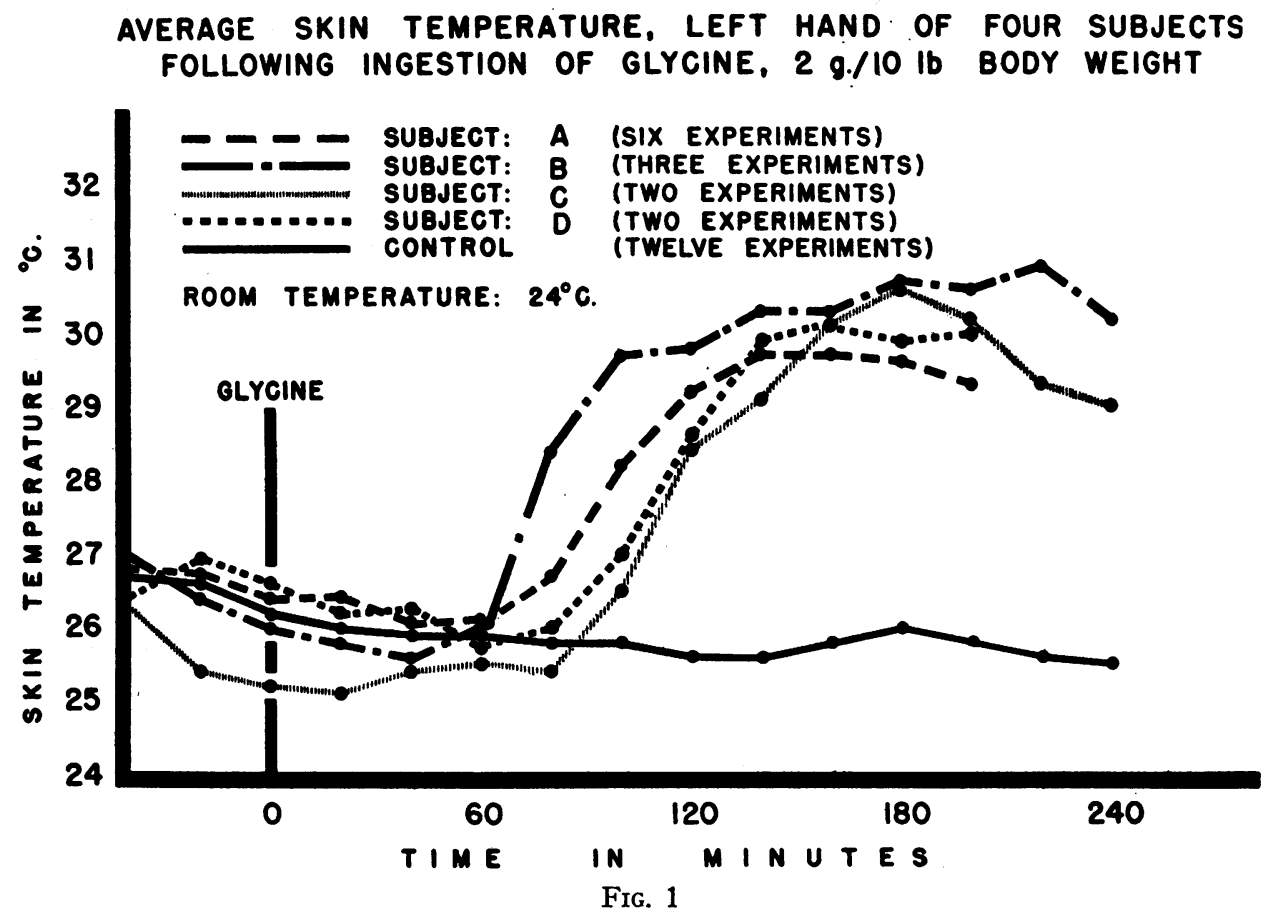


A slight but significant increase in toe temperature occurred after the ingestion of glycine, 2 grams/10 lbs. body weight, as compared with the controls. Skin temperature of the right great toe decreased an average of $0.6 \mathrm{C} .{ }^{\circ}$ for the control series while in the glycine series an average maximum increase of $1.8 \mathrm{C}^{\circ}$ was observed. These figures were obtained by averaging the maximum increase (or minimum decrease) occurring 80 or more minutes after ingestion of glycine or, in the control series, 80 or more minutes after hand skin temperature had reached equilibrium.

The control and the glycine series demonstrated no significant differences in skin temperature of forehead, forearm, back, abdomen or thigh; nor were there any significant changes in rectal temperature.

Peripheral blood flow. At an environmental temperature of $24^{\circ} \mathrm{C}$., ingestion of glycine in each of the four dosages employed, resulted in significant increase in blood flow through the hand as measured by venous occlusion plethysmography. The average maximum increases in flow following the administration of $1,2,3$, and 4 grams of glycine per $10 \mathrm{lbs}$. body weight were: $1.6 \mathrm{cc}$., 2.3 cc., $3.6 \mathrm{cc}$., and $3.9 \mathrm{cc} . / 100 \mathrm{cc}$. limb tissue/minute, the maximum amount of blood passing through the hand being approximately 2.5 to seven times the control flow. The statistical probability that these increases might have been due to chance is less than .01; the changes in blood flow paralleled the changes in hand skin temperature closely.

Oxygen consumption. Oxygen consumption, as determined by gas analysis of samples obtained from a 100-liter, open-circuit Tissot apparatus, increased after ingestion of glycine in 11 out of 12 experiments in which accurate measurements could be made. The changes in oxygen consumption ranged from 0 to $30 \%$ increase over the basal values. The rather marked variation between subjects and within the same individual in different experiments, is probably referable to (1) failure to attain a basal state initially, and (2) differences in the rate of absorption of the drug. With the optimum glycine dosage of 2 grams/10 lbs. body weight, the average rise in oxygen consumption was $13 \%$ at an environmental temperature of $24^{\circ}$ C. Increases in oxygen consumption did not appear to be related significantly to the presence or absence of nausea.
Studies at an environmental temperature of $18^{\circ} \mathrm{C}$.

Eight experiments were conducted on two men at an ambient temperature of $18^{\circ} \mathrm{C}$. At this temperature, almost maximal peripheral vasoconstriction obtains in the lightly clad subject at equilibrium with the environment. Glycine, in the four dosages mentioned previously, was administered and the experiments were identical to those described above except for the different environmental temperature. A comparison of the glycine series with the control series revealed no significant differences in skin temperature or peripheral blood flow. In neither series did any rise in skin temperature or increase in blood flow through the hand occur. Oxygen consumption in the glycine series was usually greater than in the control series but the day-to-day variations were much more marked than at an environmental temperature of $24^{\circ} \mathrm{C}$. This difference was probably due to fluctuations in muscular tensing caused by the cold stimulus. Gross shivering was never noted, although the subjects frequently complained of chilly sensations.

Studies at an environmental temperature of $30^{\circ} \mathrm{C}$.

Glycine, administered in four experiments conducted on two subjects at an ambient temperature of $30^{\circ} \mathrm{C}$., produced no rise in the already high skin temperature and no significant increase in peripheral blood flow as compared with the control series. No significant changes in rectal temperature occurred. Little or no change in oxygen consumption was observed in either series at this temperature.

\section{dl phenylalanine}

Because of its high S.D.A., the effects of phenylalanine on skin temperature and peripheral blood flow were of considerable interest. This amino acid, however, proved so distasteful to the subjects and produced such severe nausea that it was possible to complete only three experiments on three men. These were conducted at a room temperature of $24^{\circ} \mathrm{C}$. In one of the tests an amount equal to only 0.5 gram $/ 10 \mathrm{lbs}$. body weight could be swallowed by Subject C. This produced an increase in hand skin temperature equal to $1.9 \mathrm{C}$. $^{\circ}$ but no appreciable rise in blood flow through the hand. Subjects A and B were able to ingest 1 gram/10 lbs. body weight and 1.3 grams $/ 10 \mathrm{lbs}$. 
body weight, respectively. The former dose produced a maximal hand skin temperature increase of $3.9 \mathrm{C} .{ }^{\circ}$ and resulted in a blood flow through the hand equal to 4.8 times the basal flow (an increase of $3.0 \mathrm{cc} . / 100 \mathrm{cc}$. limb volume/minute). The latter dose caused an increase of $7.2 \mathrm{C} .^{\circ}$ in hand skin temperature and increased the peripheral blood flow 4.1 times (an increase of $3.1 \mathrm{cc}$./ $100 \mathrm{cc}$. limb volume/minute). There was also a slight but significant increase in toe temperature. Phenylalanine, in a dosage of 1.3 grams/10 lbs. body weight, resulted in a $6 \%$ rise in oxygen consumption.

In these three experiments no effects on either rectal temperature or skin temperature elsewhere in the body were observed following ingestion of phenylalanine.

$l(+)$ glutamic acid, $l(+)$ histidine monohydrochloride, $l(-)$ tyrosine, $l(-)$ leucine, $d l$ methionine

Glutamic acid was used in five experiments conducted on two subjects at an environmental temperature of $24^{\circ} \mathrm{C}$. The dosages employed were 1 gram/10 lbs. body weight (two experiments), 1.5 grams/10 lbs. body weight (one experiment), and 2 grams $/ 10 \mathrm{lbs}$. body weight (two experiments). No statistically significant changes in skin temperatures, rectal temperatures or blood flow through the hand occurred after administration of this substance. Oxygen consumption was increased an average of $8 \%$ over basal levels following ingestion of 2 grams $/ 10 \mathrm{lbs}$. body weight.

One man, Subject D, was given histidine on three occasions in dosages of 0.5 grams, 1.5 grams, and 2 grams/10 lbs. body weight at an environmental temperature of $24^{\circ} \mathrm{C}$. Very slight, and questionably significant, rises in hand skin temperature and peripheral blood flow were observed following ingestion of the larger doses. A comparable increase in toe temperature also occurred. No significant changes in rectal temperature or in skin temperatures elsewhere were noted, nor was there any increase in oxygen consumption. In the four experiments in which tyrosine, leucine, and methionine were administered (room temperature $24^{\circ} \mathrm{C}$.), no effects on skin temperature, rectal temperature or peripheral blood flow were demonstrated.
Relationship between total oxygen consumption, blood flow through the hand and skin temperature of the hand

No consistent relationships between either total oxygen consumption and hand skin temperature or total oxygen consumption and peripheral blood flow were observed in this investigation. High skin temperatures and flows occurred as frequently with low oxygen consumption values as with high ones and vice versa.

The data were analyzed to determine the possible existence of a time factor. Skin temperatures and blood flows were compared (1) at the time of maximum increase in oxygen consumption and (2) at 30-minute intervals before and after the maximum increase in metabolism. No clearcut relationship was demonstrated in either case. Total heat production was also measured in the control series. In these experiments blood flow and skin temperature remained quite constant, though oxygen consumption varied considerably from day to day for a particular individual. Here again, no relationships between metabolic activity and blood flow or skin temperature were noted.

At an environmental temperature of $24^{\circ} \mathrm{C}$., a highly significant correlation of .88 was found to exist between hand skin temperature and blood flow through the hand. The curve expressing the relationship between these two variables tends to become asymptotic at a skin temperature of $34^{\circ} \mathrm{C}$. (Figure 2).

\section{DISCUSSION}

These studies were initiated in an attempt to determine quantitatively the increase in peripheral blood flow and skin temperature reported to occur as a result of S.D.A. $(12,13)$. Of the seven amino acids used, five possess high S.D.A. (glycine, phenylalanine, tyrosine, glutamic acid, and leucine). Although no consistent relationships between S.D.A. and peripheral blood flow were observed, it should be emphasized that the lack of correlation between cellular energy exchange and peripheral blood flow in these studies applies only to relatively small changes in total oxygen consumption. Under circumstances in which massive metabolic differences are induced, a significant relationship may well obtain. 


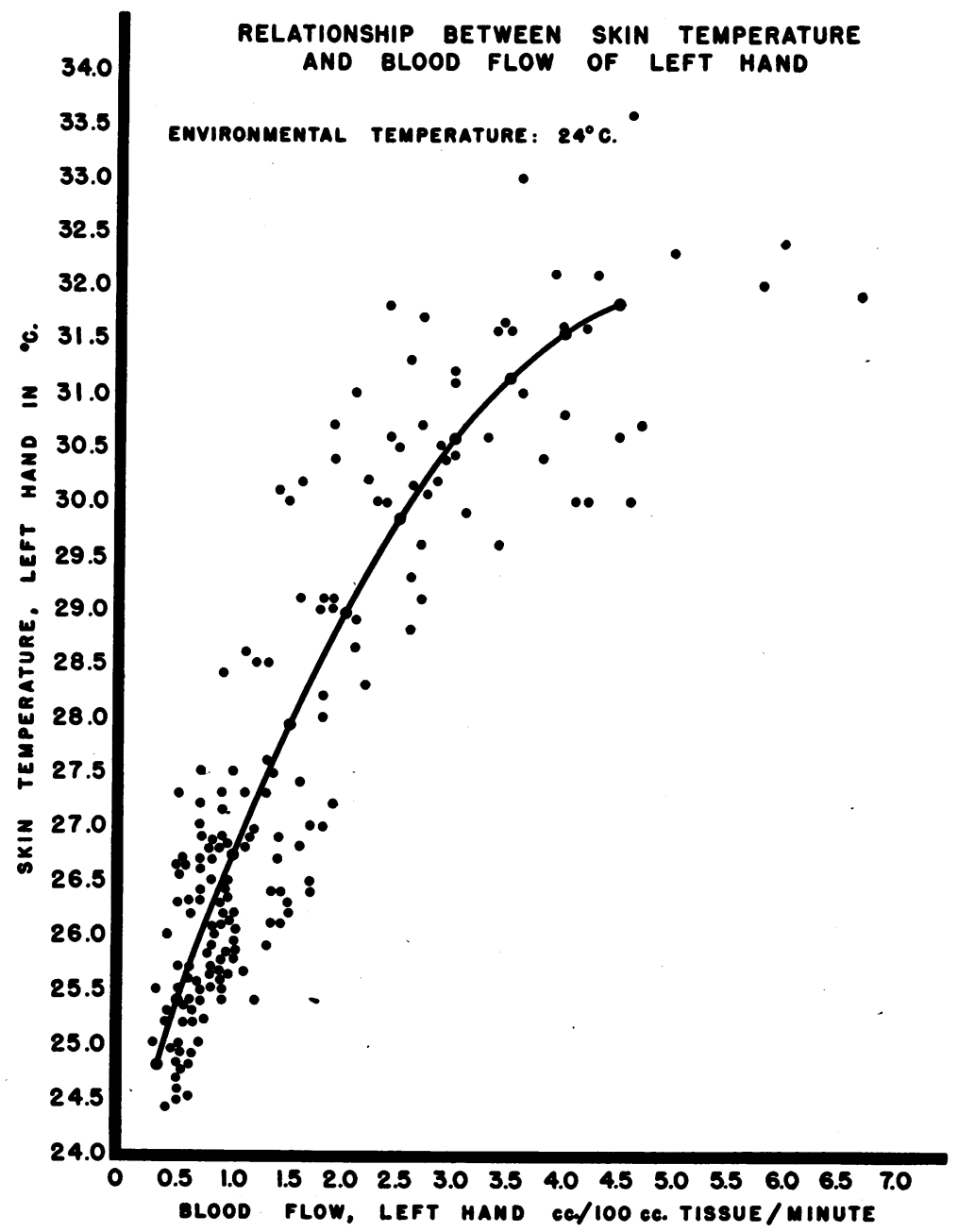

FIg. 2

That the ingestion of glycine exerts an effect upon the peripheral vascular bed under certain conditions, seems evident from this study. If this effect is not caused by the S.D.A., however, to what can it be attributed? The metabolism of glycine differs from that of other amino acids in several important respects. Gutman and Alexander (18), using specific methods for the determination of glycine, administered the amino acid to 40 subjects in dosages of 1 gram per $10 \mathrm{lbs}$. body weight. They found that, following ingestion of this substance, its concentration rises rapidly in plasma and erythrocytes, attaining its highest peak in from one to one and a half hours. The speed with which ingested glycine is absorbed into the blood stream is interesting, but the slowness with which the blood stream is completely cleared of ingested glycine is more remarkable and stands in contradistinction to the behavior of other amino acids tested, which are rapidly removed $(19,20)$. Its accumulation in other tissues is also unique. It has been demonstrated that glycine is the only amino acid which causes an increase in the amino nitrogen of muscle, as well as a greater rise in liver amino nitrogen than any other amino acid (21). The persistence of this substance in the body may well be due to a reduction in glomerular filtration and a high rate of renal tubular reabsorption for glycine $(22,23)$. It is possible that the peripheral vascular effects of glycine may be related in some manner to the uniquely high amino nitrogen content of muscle which occurs following 
ingestion of this substance and to the extremely slow rate at which it is cleared from the blood and tissues.

In these experiments, the only sites at which skin temperature rises occurred after the administration of certain amino acids were the hands and toes. The vascular anatomy of these two areas is different from the peripheral vascular bed elsewhere in that arteriovenous shunts are present in the toes, fingers, and thenar and hypothenar eminences (24). Differences between the physiological reactions of blood vessels at these sites and the peripheral vascular bed in other portions of the body have been demonstrated by numerous investigators (25 to 29 ).

It should be noted that the slight rises in toe temperature are probably more significant than the absolute figures indicate since in almost all experiments the toe was still cooling down when the amino acid was administered. Because of this, the "equilibrium temperature" assumed for the toe was usually somewhat higher than the true equilibrium temperature.

The failure of glycine to produce any changes in peripheral blood flow or skin temperature at low $\left(18^{\circ} \mathrm{C}\right.$.) ambient temperatures is in agreement with the findings of Ferris and his associates, who demonstrated that under cold ambient conditions it is extremely difficult to induce vasodilatation (30). It is evident that, in the present investigation, the neurogenic stimulus of cold was preponderant and could not be overcome by glycine. At an ambient temperature of $30^{\circ} \mathrm{C}$., blood flow and skin temperature were extremely high before the glycine was administered and very little additional vasodilatation could be effected. Similar observations have been made with other vasodilator drugs $(31,32)$.

It is the opinion of the author that glycine is of little therapeutic value as a vasodilating agent. In our experience, direct or indirect vasodilatation in the extremities can most easily and effectively be achieved by the application of heat to various body areas (33).

\section{SUM MARY}

1. Skin and rectal temperatures, total oxygen consumption, and blood flow through the hand have been studied in four healthy young males before and after the oral administration of various amino acids.

2. At an environmental temperature of $24^{\circ} \mathrm{C}$., ingestion of glycine caused a significant rise in skin temperature of the hand. In these experiments the average maximum increases in hand skin temperature following the administration of $1,2,3$, and 4 grams of glycine $/ 10 \mathrm{lbs}$. body weight were $3.5 \mathrm{C}^{\circ}, 4.8 \mathrm{C} .^{\circ}, 5.4 \mathrm{C} .^{\circ}$, and $7.7 \mathrm{C} .^{\circ}$, respectively. Hand skin temperature rises were accompanied by similar, though less marked increases in toe temperature.

3. At an environmental temperature of $24^{\circ} \mathrm{C}$., ingestion of glycine in the four dosages employed, resulted in a significant increase in blood flow through the hand as measured by venous occlusion plethysmography. Average maximum flows amounted to 2.5 to seven times the control flow.

4. The increases in blood flow and hand skin temperature generally became apparent about 80 minutes after ingestion of glycine and were most marked approximately 180 minutes after ingestion.

5. No significant changes in rectal temperature or skin temperatures elsewhere in the body were observed.

6. At environmental temperatures of $18^{\circ} \mathrm{C}$. and $30^{\circ} \mathrm{C}$., no significant changes in rectal temperature, skin temperatures, or peripheral blood flow occurred after the administration of glycine.

7. At an environmental temperature of $24^{\circ} \mathrm{C}$., ingestion of $\mathrm{dl}$ phenylalanine effected increases in hand and toe temperatures and blood flow through the hand similar to those observed with glycine.

8. At an environmental temperature of $24^{\circ} \mathrm{C}$., oral administration of $1(+)$ histidine monohydrochloride resulted in very slight and questionably significant increases in hand skin temperature and blood flow through the hand.

9. Ingestion of $1(+)$ glutamic acid, $1(-)$ tyrosine, $1(-)$ leucine and $\mathrm{dl}$ methionine had no effect upon rectal temperature, skin temperature or peripheral blood flow.

10. Although five of the seven amino acids used in these studies caused a definite increase in oxygen consumption, no consistent quantitative relationships between total oxygen consumption and skin temperature or total oxygen consumption and peripheral blood flow were demonstrated. 


\section{ACKNOWLEDGMENT}

We are indebted to Drs. Harwood S. Belding, Eugene M. Landis, Benjamin Alexander and Mortimer E. Bader for helpful suggestions relating to these experiments, and to $\mathrm{Mr}$. James Collins for the illustrative material.

\section{BIBLIOGRAPHY}

1. Burton, A. C., and Murlin, J. R., Human calorimetry ; temperature distribution, blood flow, and heat storage in the body in basal condition and after ingestion of food. J. Nutrition, 1935, 9, 281.

2. Williams, H. B., Richie, J. A., and Lusk, G., Animal calorimetry; metabolism of the dog following the ingestion of meat in large quantity. J. Biol. Chem., 1912-13, 12, 349.

3. Herrick, J. F., Essex, H. E., Mann, F. C., and Baldes, E. J., The effect of digestion on the blood flow in certain vessels of the dog. Am. J. Physiol., 1934, 108, 621.

4. Booth, G., and Strang, J. M., Changes in the temperature of the skin following the ingestion of food. Arch. Int. Med., 1936, 57, 533.

5. Abramson, D. I., and Fierst, S. M., Peripheral vascular responses in man during digestion. Am. J. Physiol., 1941, 133, 686.

6. Ipsen, J., Das Verhalten der Arterien bei thyreotoxischen Zuständen, besonders beim Morbus Basedowii. Arch. f. klin. Chir., 1932, 169, 585.

7. Kirklin, O. L., Plummer, W. A., and Sheard, C., Measurements of the skin temperatures of the extremities in exophthalmic goiter, before and after medical and surgical treatment. Proc. Staff Meet., Mayo Clin., 1940, 15, 774.

8. Stewart, H. J., and Evans, W. F., Peripheral blood flow in hyperthyroidism. Am. Heart J., 1940, 20, 715.

9. Eichna, L. W., and Wilkins, R. W., Blood flow to the forearm and calf; thyroid activity: observations on the relation of blood flow to basal metabolic rate. Bull. Johns Hopkins Hosp., 1941, 68, 512.

10. Abramson, D. I., and Fierst, S. M., Resting peripheral blood flow in the hyperthyroid state. Arch. Int. Med., 1942, 69, 409.

11. Rapport, D., and Beard, H. H., The effects of protein split-products upon metabolism. III. J. Biol. Chem., 1928, 80, 413.

12. Gubner, R., and DiPalma, J. R., Effect of glycine. on peripheral blood flow. Proc. Soc. Exper. Biol. \& Med., 1945, 59, 170.

13. Gubner, R., DiPalma, J. R., and Moore, E., Specific dynamic action as a means of augmenting peripheral blood flow. Am. J. M. Sc., 1947, 213, 46.

14. Nord, F., and Deuel, H. J., Jr., Animal calorimetry; the specific dynamic action of glycine given orally and intravenously to normal and to adrenalectomized dogs. J. Biol. Chem., 1928, 80, 115.
15. Weiss, R., and Rapport, D., Animal calorimetry; the interrelations between certain amino acids and proteins with reference to their specific dynamic action. J. Biol. Chem., 1924, 60, 513.

16. Forster, R. E., II, Ferris, B. G., Jr., and Day, R., The relationship between total heat exchange and blood flow in the hand at various ambient temperatures. Am. J. Physiol., 1946, 146, 600.

17. Fisher, R. A., Statistical Methods for Research Workers. Oliver and Boyd, Edinburgh, 1941.

18. Gutman, G. E., and Alexander, B., Studies of amino acid metabolism. I. Blood glycine and alanine and their relationship to the total amino acids in normal subjects. J. Biol. Chem., 1947, 168, 527.

19. Van Slyke, D. D., and Meyer, G. M., The fate of protein digestion products in the body. III. The absorption of amino-acids from the blood by the tissues. J. Biol. Chem., 1913-14, 16, 197.

20. Silber, R. H., Seeler, A. O., and Howe, E. E., Urinary excretion of $\alpha$-amino nitrogen following intravenous administration of amino acid mixtures. J. Biol. Chem., 1946, 164, 639.

21. Luck, J. M., Metabolism of amino acids. J. Biol. Chem., 1928, 77, 13.

22. Pitts, R. F., A renal reabsorptive mechanism in the dog common to glycin and creatine. Am. J. Physiol., 1943, 140, 156.

23. Pitts, R. F., A comparison of the renal reabsorptive processes for several amino acids. Am. J. Physiol., 1943, 140, 535.

24. Grant, R. T., and Bland, E. R., Observations on arteriovenous anastomoses in human skin and in the bird's foot, with special reference to the reaction to cold. Heart, 1929-31, 15, 385.

25. Kunkel, P., Stead, E. A., Jr., and Weiss, S., Blood flow and vasomotor reactions in the hand, forearm, foot and calf in response to physical and chemical stimuli. J. Clin. Invest., 1939, 18, 225.

26. Abramson, D. I., and Ferris, E. B., Jr., Responses of blood vessels in the resting hand and forearm to various stimuli. Am. Heart J., 1940, 19, 541.

27. Wilkins, R. W., and Eichna, L. W., Blood flow to the forearm and calf. I. Vasomotor reactions: role of the sympathetic nervous system. Bull. Johns Hopkins Hosp., 1941, 68, 425.

28. Abramson, D. I., Katzenstein, K. H., and Ferris, E. B., Jr., Observations on reactive hyperemia in various portions of the extremities. Am. Heart J., 1941, 22, 329.

29. Grant, R. T., and Pearson, R. S. B., The blood circulation in the human limb: observations on the differences between the proximal and distal parts and remarks on the regulation of body temperature. Clin. Sc., 1938, 3, 119.

30. Ferris, B. G., Jr., Forster, R. E., II, Pillion, E. L., and Christensen, W. R., Control of peripheral blood flow: responses in the human hand when the extremities are warmed. Am. J. Physiol., 1947, 150, 304. 
31. Montgomery, H., Holling, H. E., and Friedland, C. $K$., Effect of iontophoresis with acetyl- $\beta$-methylcholine chloride on rate of peripheral blood flow. Am. J. M. Sc., 1938, 195, 794.

32. Abramson, D. I., Fierst, S. M., and Flachs, K., Evaluation of the local vasodilator effect of acetyl- $\beta$ methylcholine chloride (mecholyl) by iontophoresis. Am. Heart J., 1942, 23, 817.
33. Bader, M. E., Macht, M. B., and Pillion, E. L., Peripheral vascular effects produced by localized warming of various skin areas. Federation Proc., 1948, 7, 4.

34. Macht, M. B., and Pillion, E. L., Changes in skin temperature and blood flow of the hand following the ingestion of certain amino acids. Federation Proc., 1948, 7, 75. 